\title{
Budaya Tabu pada Masyarakat Banyumas
}

\section{Taboo Culture in Banyumas Society}

\author{
Muhammad Faisal Bisma1), Rosdiana Puspita Sari'2) \& \\ Gigih Ariastuti Purwandari ${ }^{2)}$
}

1) Magister Administrasi Publik, Fakultas Ilmu Sosial dan Ilmu Politik, Universitas Jenderal Soedirman, Indonesia

2)Bahasa dan Sastra Inggris, Fakultas Ilmu Budaya, Universitas Jenderal Soedirman, Indonesia

Diterima: 21 Mei 2021 Direview: 21 Mei 2021; Disetujui: 06 Agustus 2021 *Coresponding Email: rosdiana.puspita.sari@unsoed.ac.id

\section{Abstrak}

Penelitian ini bertujuan untuk mengetahui budaya tabu yang ada pada masyarakat Banyumas. Banyumas adalah salah satu kabupaten di Jawa Tengah. Metode penelitian yang digunakan adalah deskriptif kualitatif dimana metode ini tidak menggunakan angka atau hitungan matematik maupun statistik pada interpretasi datanya. Sumber data diperoleh dari interview terhadap anggota masyarakat serta sumber lainnya seperti studi pustaka mengenai budaya tabu yang terdapat di Banyumas dan sekitarnya. Hasil penelitian menunjukkan bahwa terdapat enam jenis tabu yang ada di dalam masyarakat Banyumas sesuai dengan klasifikasi yang dibuat oleh Wardhaugh, yaitu tabu dalam hal sex (seks), death (kematian), excretion (kotoran), bodily function (fungsi organ tubuh), religious matters (kepercayaan terhadap sesuatu) dan politics (politik). Kepercayaan terhadap sesuatu adalah hal yang sering muncul di dalam budaya tabu masyarakat Banyumas. Masyarakat percaya bahwa budaya tabu tersebut dilarang untuk dilakukan karena jika dilakukan akan ada akibat atau sanksi yang tidak baik yang akan diterima oleh pelakunya.

Kata Kunci: Budaya; Tabu; Sanksi

\begin{abstract}
This research aims to know taboo cultures in Banyumas Society. Banyumas is one of the regencies in Central Java. The method that is used is qualitative descriptive. This method does not use numeric or mathematical and statistical count in the interpretation of data. The source of the data are from the interview and literature review about taboo culture in Banyumas and surrounding. The result of the research shows that there are six kinds of taboo cultures in Banyumas based on Wardhaugh's classification, which are sex, death, excretion, bodily function, religious matters and politics. Religious matter is the most taboos that appear in Banyumas culture. The society believe that those taboo cultures are prohibited to do because those who violate that taboo will get unexpected sanction and punishment.
\end{abstract}

Keywords: Culture; Taboo; Sanction

How to Cite: Bisma, M.F., Sari, R.P. \& Purwandari, G.A. (2021). Budaya Tabu pada Masyarakat Banyumas. Journal of Education, Humaniora and Social Sciences (JEHSS). 4 (2): 711-717. 


\section{PENDAHULUAN}

Budaya merupakan hal yang erat kaitanya dengan kehidupan manusia yang hidup di dalam suatu kelompok masyarakat. Manusia hidup dalam kelompok sosial yang memiliki kebiasaan, lingkungan, bahasa, mata pencaharian maupun warisan sejaran yang berbeda yang akhirnya membentuk kebudayaan yang berbeda antara satu kelompok dengan kelompok lainya. Budaya masyarakat Jawa misalnya akan berbeda dengan budaya masyarakat Batak. Beberapa hal di dalam suatu budaya akan dianggap sopan atau biasa saja tetapi di dalam budaya lain dapat dianggap tidak sopan atau bahkan tabu atau dilarang. Menurut Koentjaraningrat (1983), kebudayaan adalah keseluruhan sistem gagasan, tindakan dan hasil karya manusia dalam kehidupan masyarakat yang dijadikan milik diri manusia dengan belajar. Karena hampir semua tindakan manusia diperoleh dari proses belajar, maka hampir semua tindakan manusia adalah kebudayaan. Kebudayaan tidak diturunkan melalui faktor genetik melainkan dipelajari di dalam kehidupan. Manusia mempelajari kebudayaan mereka melalui proses kehidupan dan interaksi antar anggota kelompoknya. Kebudayaan ini diajarkan turun temurun dari nenek moyang. Misalnya pada upacara adat yang diadakan oleh budaya tertentu yaitu sekaten, begalan dan ruwat. Budaya tersebut sudah dilakukan secara turun temurun dengan ketentuan waktu dan kondisi tertentu di dalam masyarakat.

Manusia hidup bermasyarakat dan melahirkan serangkaian kebiasaaan yang akhirnya menjadi suatu budaya. Setiap daerah memiliki budaya masing-masing. Hal ini terjadi karena berbagai faktor seperti halnya faktor alam, tingkat pendidikan, kemajuan teknologi dan sebagaianya. Masyarakat yang hidup di daerah pesisir pantai tentu memiliki kebiasaan dan budaya yang berbeda dengan masyarakat yang hidup di daerah agrikultur yang mayoritas penduduknya adalah bertani. Faktor pendidikan dan teknologi juga sangat berpengaruh terhadap pola pikir serta interpretasi seseorang terhadap suatu kepercayaan maupun pemikiran.

Ide-ide dan gagasan manusia banyak yang hidup bersama dalam kehidupan manusia, melekat dan memberi jiwa kepada masyarakat. Gagasan- gagasan dan ide ini disebut adat- istiadat. Tingkat paling tinggi dan paling abstrak dari adat istiadat adalah sistem nilai budaya karena nilainilai budaya merupakan pedoman yang memberi arah dan orientasi terhadap hidup. Di dalam suatu masyarakat juga dikenal norma-norma. Ada norma yang sangat berat sehingga apabila terjadi pelanggaran terhadap norma tersebut akan ada akibat yang tidak diinginkan misalnya saja dalam pelanggaran budaya yang dianggap tabu oleh masyarakat. Di sisi lain ada juga norma-norma yang apabila melanggar norma tersebut akibatnya bukan hukuman melainkan tertawaan, ejekan, atau penggunjingan. Tabu sendiri merupakan bagian dari budaya suatu masyarakat yang dianggap suci sehingga tidak boleh dilakukan dan menjadi sebuah pantangan (AR dkk, 2015). Selain itu, di beberapa budaya ada pula makanan yang dianggap suci sehingga tabu untuk dimakan. Misalnya di Bali yang menganggap bahwa sapi merupakan binatang suci kendaraan para dewa sehingga masyarakat tabu untuk menyembelih sapi sebagai makanan mereka. Hal ini sangat dipengaruhi oleh faktor yang berhubungan dengan religi sehingga pada masyarakat yang memiliki latar belakang agama yang berbeda tentunya akan meiliki pandangan dan kepercayaan yang berbeda pula. Penelitian yang dilakukan oleh Auditna dkk (2019) menunjukkan bahwa di desa Bulubete, Kecamatan Dolo Selatan, Kabupaten Sigi terdapat beberapa makanan yang dilarang dikonsumsi oleh ibu hamil seperti cumi-cumi, ikan cakalang, nangka, nanas, belut, gurita, kerang, udang, dan sebagainya. Kepercayaan terhadap hal ini sangat erat dengan faktor budaya serta tingkat pendidikan masyarakat sekitarnya. Menurutnya, kepercayaan ini tidak memiliki dasar ilmiah dan hubungan yang rasional antara ibu hamil dengan larangan memakan cumi-cumi. Namun, masyarakat yang percaya akan hal tabu ini akan memilih untuk taat dan tidak melanggar karena takut akan dampak negatif baik yang bersifat abstrak ataupun nyata. Hasil penelitianya juga menunjukkan bahwa hal ini juga erat kaitanya dengan faktor pendidikan. Masyarakat yang tingkat pendidikanya tinggi akan cenderung tidak mempercayai hal tersebut. Namun, masyarakat yang memiliki pendidikan yang kurang akan cenderung mempercayai dan tidak bersikap skeptis terhadap larangan-larangan tersebut.

Ketika bermasyarakat, manusia terikat oleh aturan atau norma tertentu baik itu yang harus ditaati maupun yang dilarang untuk dilakukan. Jika hal yang dilarang tersebut dilakukan, manusia 
akan mendapatkan sanksi. Hal yang dilarang inilah yang disebut sebagai hal yang tabu. Tabu adalah hal-hal yang dilarang untuk dilakukan di dalam suatu budaya masyarakat tertentu karena jika dilakukan akan mengakibatkan dampak yang tidak baik bagi pelakunya (Wardhaugh, 2006). Ketika suatu hal di dalam sebuah budaya dianggap tabu maka hal tersebut dilarang atau pantang untuk dilakukan. Hal tabu hampir selalu ada di berbagai budaya khususnya pada aktifitas sosial masyarakat (Humaeni, 2015).

Masyarakat mempercayai bahwa pelanggaran terhadap bahasa dan budaya tabu akan mengakibatkan sanksi baik secara fisik maupun metafisik (Alan dan Burridge, 2006). Sanksi tersebut misalnya, pelanggar akan terkena sakit atau bahkan meninggal. Sanksi secara sosial juga dapat terjadi yaitu berupa pengasingan, penghinaan atau dijauhi oleh masyarakat lainya. Berbagai budaya di setiap daerah memiliki hal yang dianggap tabu. Budaya tabu ini juga terdapat di dalam masyarakat Banyumas. Banyumas merupakan sebuah Kabupaten di Provinsi Jawa Tengah yang penuturnya menggunakan dialek yang berbeda dengan masyarakat di daerah Jogja-Solo. Dialek yang digunakan adalah bahasa Jawa dialek Banyumas atau yang terkenal dengan bahasa Ngapak. Dialek Banyumas merupakan salah satu dialek yang mengalami retensi atau masih mempertahankan morfem- morfem bahasa Jawa kuno, sehingga bahasa Jawa dialek Banyumas berbeda dengan bahasa Jawa dialek Jogja -Solo yang sudah mengalami inovasi (Zoetmulder dan Poedjawijatna, 1993). Inovasi tersebut terjadi selama ratusan tahun sehingga terjadi perubahan bahasa (language change). Hal yang menarik dari Banyumas adalah masyarakatnya dapat dengan mudah memahami dialek Joga-Solo. Namun, masyarakat penutur Jogja-Solo yang merupakan penutur bahasa Jawa standar cenderung sulit untuk memahami dialek Jawa Banyumas. Selain mengalami pemertahanan bahasa, masyarakat penutur bahasa Jawa dialek Banyumas pun masih mempertahankan serangkaian budaya yang tetap terjaga, termasuk bahasa dan budaya yang dianggap tabu dan dilarang dilakukan oleh masyarakat Banyumas.

Istilah tabu di dalam bahasa Jawa Banyumas biasanya disebut dengan ora ilok, sedangkan di dalam bahasa Sunda disebut pamali. Smith (2007) menyatakan bahwa tabu merupakan suatu gagasan yang bersifat memaksa dan menyiksa serta mengancam masyarakatnya karena tidak boleh dilakukan atau dibicarakan secara langsung di hadapan umum. Kata tabu atau dalam bahasa Inggris disebut dengan taboo berasal dari bahasa Tongan yang muncul pada sekitar abad ke 18 (Alan dan Burridge, 2006). Tabu memiliki beberapa istilah di setiap bahasa. Di dalam bahasa Jawa dialek Banyumas, tabu disebut dengan ora ilok, di dalam bahasa Sunda disebut dengan pamali, di dalam bahasa Minang disebut sebagai pantang, sedangkan di dalam bahasa Muna disebut falia (Juansah, 2009).

Contoh budaya yang dianggap tabu tersebut misalnya masyarakat mempercayai bahwa pada bulan Suro (Muharam), masyarakat dilarang mengadakan acara hajatan seperti acara pernikahan maupun khitanan. Hal ini berhubungan dengan sebuah mitos bahwa bulan tersebut merupakan bulan dimana Ratu Pantai Selatan sedang mengadakan hajatan sehingga masyarakat dilarang mengadakan hajatan. Jika melanggar hal tersebut masyarakat akan terkena akibat yang tidak diinginkan misalnya meninggal (Sholikhin, 2010). Hal inilah yang menyebabkan sebagian masyarakat yang mempercayai budaya tersebut merasa takut jika melakukan pelanggaran (violation) terhadap budaya yang dilarang atau yang dianggap tabu.

Selain itu, contoh lain budaya tabu di kabupaten Banyumas dan sekitarnya adalah larangan bepergian jauh pada hari Sabtu pahing karena dipercaya akan mendatangkan malapetaka. Hal ini erat kaitanya dengan tragedi yang dialami oleh Adipati Wargohutomo I atau biasa disebut Adipati Wirasaba yang terbunuh pada hari Sabtu Pahing setelah memakan pindang Banyak (masakan yang terbuat dari sejenis unggas). Sebelum meninggal, sang Adipati berpesan kepada warganya untuk tidak bepergian di hari tersebut serta untuk tidak memakan pindang Banyak (Sudarmo dan Purwoko, 2009). Hal ini merupakan awal mula hari tersebut dianggap tabu oleh masyarakat Banyumas dan sekitarnya. Jika bepergian di hari Sabtu Pahing dipercaya akan mendapatkan kesulitan, sakit atau bahkan petaka seperti yang dialami oleh Adipati Wirasaba.

Hari Sabtu pahing menjadi hari yang tabu karena ada latar belakang sejarah yang terjadi pada masa lalu. Hal ini sejalan seperti apa yang disampaikan oleh Priyadi (2006) yaitu hal yang dianggap tabu memiliki hubungan sejarah dan konflik sosial maupun kepentingan yang terjadi 
pada masa lampau. Misalnya saja tabu nikah yang terjadi pada masyarakat Onje dan Cipaku di Kabupaten Purbalingga (salah satu Kabupaten yang berbatasan langsung dengan Kabupaten Banyumas). Hal ini dilandasi sebuah peristiwa konflik di masa lalu dimana Adipati Onje yang menikahi putri Cipaku bersikap semena-mena terhadap putri Cipaku sehingga menimbulkan berbagai konflik sosial lainya. Peristiwa tersebut menjadikkan masyarakat takut akan mengalami hal yang sama jika ada laki-laki Onje yang menikahi seorang wanita yang berasal dari Cipaku. Latar belakang sejarang merupakan hal yang menjadi sumber terciptanya sebuat stereotipe tertentu di dalam suatu masyarakat. Suatu kejadian digeneralisir dan dianggap akan memunculkan kejadian yang sama jika peristiwa tersebut dilakukan. Masyarakat cenderung akan menghindari hal tersebut agar terhindar dari petaka dan memiliki kehidupan yang aman dan nyaman. Hal ini juga sejalan seperti apa yang disampaikan oleh Yayuk (2019) bahwa masyarakat memiliki kecenderungan untuk menghindari perbuatan yang dianggap tabu karena adanya rasa takut dan alasan agar tercipta kehidupan yang nyaman.

Hal yang dianggap tabu ini kemudian dihindari oleh masyarakat dengan tujuan untuk menghindari serangkaian konflik baik itu konflik personal, konflik dengan keluarga maupun konflik dengan masyarakat sekitar. Hal ini agar tercipta suasana yang harmonis antar kehidupan bermasyarakat (Barus dkk, 2018). Pendapat serupa juga disampaikan oleh Mondolalo (2015) bahwa budaya tabu merupakan bentuk kearifan lokal masyarakat untuk mengatur serta menjaga tatanan kehidupan masyarakat serta menyampaikan pesan kepada masyarakat mengenai perbuatan yang baik dan perbuatan yang tidak baik untuk dilakukan sehingga tercipta tatanan kehidupan yang baik.

Berdasarkan penjelasan di atas, penelitian ini bertujuan untuk mendeskripsikan budaya tabu apa saja yang terdapat di dalam masyarakat Banyumas dan sekitarnya serta jenis tabu apakah yang paling banyak muncul di dalam budaya Banyumas. Data budaya tabu di klasifikasikan sesuai dengan teori yang disampaikan oleh Wardhaugh (2006) yang meliputi tabu dalam hal sex (seks), death (kematian), excretion (kotoran), bodily function (fungsi organ tubuh), religious matters (kepercayaan terhadap sesuatu) dan politics (politik).

\section{METODE PENELITIAN}

Penelitian ini dilakukan dengan menggunakan metode deskriptif kualitatif dimana metode ini tidak menggunakan angka atau hitungan matematik maupun statistik pada interpretasi datanya (Anggito dan Setiawan, 2018). Penelitian kualitatif bertujuan untuk menginterpretasikan fenomena sosial yang terjadi di masyarakat. Teknik yang digunakan dalam mengumpulkan data adalah teknik wawancara. Wawancara dilakukan oleh peneliti kepada tokoh masyarakat di daerah Banyumas. Hasil dari wawancara tersebut direkam dan dicatat. Selain itu juga peneliti melakukan teknik dokumentasi terhadap proses wawancara tersebut. Selain wawancara, sumber data juga diperoleh dari studi pustaka mengenai budaya tabu yang terdapat di Banyumas dan sekitarnya. Selain itu, teknik pengumpulan data juga dilakukan dengan melakukan observasi partisipan serta terjun langsung ke masyarakat Banyumas. Data yang diperoleh kemudian diklasifikasikan berdasarkan klasifikasi tabu yang dikemukakan oleh Wardhaugh (2006) yang meliputi tabu dalam hal sex (seks), death (kematian), excretion (kotoran), bodily function (fungsi organ tubuh), religious matters (kepercayaan terhadap sesuatu) dan politics (politik).

\section{HASIL DAN PEMBAHASAN}

Data budaya tabu di klasifikasikan sesuai dengan teori yang disampaikan oleh Wardhaugh (2006) yang meliputi tabu dalam hal sex (seks), excretion (kotoran), bodily function (fungsi organ tubuh), religious matters death (kematian),(kepercayaan terhadap sesuatu) dan politics (politik) sebagai berikut:

\section{Seks}

Seks merupakan hal yang sering dianggap tabu di berbagai budaya. Masyarakat bahkan tabu untuk membicarakanya terlebih jika berbicara mengenai seks dengan lawan jenis. Berdasarkan penelitian yang dilakukan oleh Tajgozari dan Sahragard (2018), seks merupakan hal yang paling 7 http://mahesainstitute.web.id/ojs2/index.php/jehss 
dianggap tabu di dalam budaya warga Iran selain umpatan yang disampaikan ketika orang sedang marah. Hal ini menunjukkan bahwa tabu dalam hal seks juga terjadi di budaya lain yaitu di Iran. Hal mengenai seks yang dianggap tabu dalam budaya Banyumas adalah mengenai waktu dan harihari dimana pasangan suami istri dilarang berhubungan yaitu saat hari lahir (weton) masingmasing pasangan , hari lahir anak-anak, hari kematian orang tua serta tanggal 1 Muharram (1 Sura). Hal ini karena hari-hari tersebut dianggap keramat dan harus dihormati oleh masyarakat Banyumas sehingga masyarakat dilarang melakukan hubungan badan dengan pasangan.

\section{Death (Kematian)}

Hal-hal yang berhubungan dengan kematian sering diasosiasikan dengan sesuatu yang menakutkan sehingga banyak yang ditabukan. Misalnya jika ada orang meninggal, bayi/batita diberi sambetan (campuran dari umbi bengle dan daun dringo). Campuran tersebut kemudian diuleg dan diusapkan ke kepala, sendi-sendi tangan dan kaki anak. Jika hal ini tidak dilakukan, maka masyarakat percaya bahwa si anak akan "kesambet" oleh makhluk halus sehingga akan bertingkah aneh atau menangis terus menerus. Selain itu, masyarakat juga percaya bahwa jika ada orang meninggal, anggota keluarga diminta untuk berjalan di bawah keranda jenazah dengan tujuan supaya anggota keluarganya tidak terus mengingat si jenazah karena jika hal tersebut tidak dilakukan maka anggota keluarganya akan terus menerus merasa kehilangan dan meratapi kepergian si jenazah. Karena alasan takut akan hal buruk atau halyang tidak diinginkan akan terjadi maka masyarakat melakukan segala ritual atau kegiatan tersebut.

\section{Excretion (Kotoran)}

Masyarakat Banyumas percaya bahwa kotoran bayi yang menempel di popok sekali pakai tidak boleh dibakar dan harus dibuang di tempat yang mengandung air agar supaya si bayi tidak terkena penyakit kulit. Selain itu, jika ada anak batita yang memakan kotoranya sendiri, bayi tersebut harus "dijual" hanya secara formalitas saja. Jadi, ada pihak keluarga atau orang lain yang seolah-olah membeli anak tersebut dengan memberikan uang secara simbolis. Namun, bayi tersebut tetap tinggal dan hidup dengan orang tuanya.

\section{Bodily Function}

Tabu jenis ini berhubungan dengan anggota badan. Misalnya orang yang hamil, jika bepergian di malam hari harus diurai rambutnya agar tidak diganggu oleh makhluk halus. Selain itu juga memotong kuku tidak boleh dilakukan di malam hari. Jika hal tersebut dilakukan maka hal buruk akan terjadi.

\section{Kepercayaan (Religious Matters)}

Dalam hal kepercayaan ada beberapa hal tabu yang dipercaya oleh masyarakat Banyumas. Pertama, masyarakat percaya bahwa mereka tidak boleh mengadakan hajatan di bulan Sura karena hari baik dan ratu pantai selatan sedang memiliki hajat sehingga masyarakatnya supaya ikut berpartisipasi menyongsong hajatan tersebut. Oleh karena itu, masyarakat dilarang mengadakan hajatan di bulan tersebut (Sholikhin, 2010). Selain hajatan, masyarakat juga dilarang mengadakan kegiatan seperti pembangunan rumah maupun pindah rumah.

Kedua, anak perempuan yang masih gadis tidak boleh duduk di pintu karena masyarakat mempercayai jika duduk di pintu nantinya akibatnya akan menjadi perawan tua. Ketiga, makanan harus dihabiskan karena kalau tidak habis nantinya ayam atau binatang peliharaanya akan mati. Keempat, menyapu rumah harus dilakukan dengan bersih jika tidak, pasanganya kelak akan buruk rupa. Hal ini erat kaitanya dengan tujuan supaya kita sebagai masyarakat bisa menanamkan budaya hidup bersih. Kelima, kalau akan pindah rumah dilarang saat naga sedang berada di arah yang sama misalnya pindah ke utara, maka naga tidak boleh sedang berada di utara. Naga merupakan sosok halus atau ghoib yang dipercaya masyarakat selalu berpindah arah. Masyarakat dilarang melakukan 
kegiatan pindah rumah serarah dengan arah posisi naga karena masyarakat percaya bahwa naga tersebut bisa 'memakan' manusia sehingga bisa memiliki dampak buruk seperti tiba-tiba terkena penyakit dan meninggal.

Keenam, jika ada anak lahir yang memiliki weton (hari lahir) sama dengan salah satu dari orang tuanya maka bayi tersebut harus "diadopsi" secara formalitas oleh orang lain atau anggota keluarga yang lain. Bayi tersebut tetap tinggal dan hidup bersama dengan orang tuanya hanya saja bayi tersebut memiliki orang tua angkat yang juga dipanggil Bapak/Mamak.

Ketujuh, beberapa anak yang lahir harus diruwat seperti anak tunggal (ontang anting), anak 2 laki-laki dan perempuan (kedana kedini), 3 anak yang terdiri dari laki-laki, perempuan dan lakilaki (sendang kapit pancuran), 5 anak laki-laki semua (pandhawa lima), 5 anak perempuan semua (pandhawa ngempani). Anak-anak tersebut bukanlah merupakan hasil dari program Kelurga Berencana tetapi lahir secara alamiah. Jika tidak diruwat maka dipercaya nantinya anak-anak tersebut akan dimakan oleh Bathara Kala.

Kedelapan, menyapu rumah harus dilakukan dari ruang depan (ruang tamu terlebih dahulu) dan diakhiri di ruang belakang. Hal ini dilakukan agar rejeki orang yang memiliki rumah tersebut terkumpul dan tidak keluar. Kesembilan, pada hari Jumat Kliwon dan Selasa Kliwon, tidak boleh menyapu rumah di pagi hari kecuali jika sudah ada tamu yang datang. Jika hal ini dilanggar maka rumah akan dikerumuni banyak semut.

\section{Politics}

Hal yang berhubungan dengan politik misalnya adalah tentang pemilihan kepala desa. Jika ada pemilihan lurah atau kepala desa, tabu melakukan muwur atau membagi-bagikan uang di pagi hari sebelum dilakukanya pilkades karena hal tersebut melanggar aturan dan jika dilakukan akan ada sanksi dari masyarakat. Selain itu juga, jika ada pemilihan kepala desa, antar calon biasanya saling bersaing. Hal yang tabu adalah meletakan telur busuk di rumah salah satu calon yang dilakukan oleh lawanya dengan tujuan agar pesaingnya tidak menjadi lurah. Hal ini juga dianggap melanggar aturan.

\section{SIMPULAN}

Simpulan dari penelitian ini adalah terdapat budaya tabu pada masyarakat Banyumas dan sekitarnya. Budaya tabu tersebut terdiri dari 6 klasifikasi yaitu tabu dalam hal sex (seks), death (kematian), excretion (kotoran), bodily function (fungsi organ tubuh), religious matters (kepercayaan terhadap sesuatu) dan politics (politik). Kepercayaan terhadap sesuatu adalah hal yang sering muncul di dalam budaya tabu masyarakat Banyumas. Masyarakat percaya bahwa budaya tabu tersebut dilarang untuk dilakukan karena jika dilakukan akan ada akibat atau sanksi yang tidak baik yang akan diterima oleh pelakunya.

\section{UCAPAN TERIMAKASIH (Optional)}

Ucapan terimakasih disampaikan kepada Lembaga Penelitian dan Pengabdian Kepada Masyarakat (LPPM) Universitas Jenderal Soedirman yang telah memberikan dukungan sehingga penelitian ini dapat terlaksana. Selain itu juga kepada semua responden yang terlibat yang sangat kooperatif dalam menjelaskan hal-hal tabu yang ada di Banyumas.

\section{DAFTAR PUSTAKA}

Alan dan Burridge, K. (2006). Forbidden Words: Taboo and the Censoring of Language. USA: Cambridge University Press.

Anggito, A dan Setiawan, J. (2018). Metodologi Penelitian Kualitatif. Sukabumi: CV Jejak.

AR, Arini dkk. (2015). Ungkapan Tabu pada Tuturan Peserta pada Acara Indonesia Lawyer Club di Stasiun TV One. Jurnal Bahasa, Sastra dan Pembelajaran, 3(1), 57-68.

Auditna, W. (2019). Persepsi Ibu Hamil terhadap Makanan Tabu di Desa Bulubete Kecamatan Dolo Selatan Kabupaten Sigi. Jurnal Kolaboratif Sains, 1(1), 460-470.

Barus= (2018). Local Wisdom of Taboos $\quad$ in Karo Language. Jurnal Language Literacy, 2 (2), 94-102.

Humaeni, A. (2015). Tabu Perempuan dalam Budaya Masyarakat Banten. Jurnal Humaniora, 27(2), 174-185. 
Juansah, D. E., (2009). Expression of Prohibition as The Representation of Taboo in Baduy Society. Jurnal LITERA, 18 (1), 36-58.

Koentjaraningrat. (1983). Pengantar Ilmu Antropologi. Jakarta: Aksara Baru

Mondolalo, D. (2015). Kajian Hermeneutik Nilai-Nilai Kearifan Lokal Kata-Kata Falia (Tabu) Masyarakat Muna. Jurnal Riksa Bahasa, 1(2), 170-176.

Priyadi, S. (2006). Konflik Sosial Tabu Nikah pada Masyarakat Pedesaan di Purbalingga dan Banyumas. Jurnal Humaniora, 18(2), 165-177.

Sholikhin, M. (2010). Misteri Bulan Suro: Perspektif Jawa Islam. Yogyakarta: Narasi.

Smith, F.A. (2007). The Taboos of Leadership. San Fransisco: Wiley.

Sudarmo, M.W. dan Bambang S.P. (2009). Sejarah Banyumas dari Masa ke Masa. Banyumas.

Tajgozari, M. dan Sahragard, R.. (2018). Iranian Adults Speakers' Perception toward Linguistics Taboos and Euphemisms in Iranian Society: A Sociolinguistics View. Jurnal Language Art, 3 (4), 33-46.

Wardhaugh, R. (2006). An Introduction to Sociolinguistics: Fifth Edition. USA: Blackwell Publishing.

Yayuk, R. (2019). Klasifikasi Tabu pada Masyarakat Banjar. Jurnal Kandai, 15(1), 27-46.

Zoetmulder dan Poedjawijatna. (1993). Bahasa Parwa II. Yogyakarta: Gadjah Mada University Press. 